\title{
Nota Científica / Short Communication \\ Redescobrindo a floresta decídua no Espírito Santo: o caso de São João de Petrópolis, Santa Teresa
}

\author{
Rediscovering the deciduous forest in Espírito Santo: \\ the case of São João de Petrópolis, Santa Teresa
}

\author{
Felipe Zamborlini Saiter ${ }^{1,2,3}$, Eduardo France Oza ${ }^{1}$, Millena Monteiro dos Santos ${ }^{1}$, \\ Silas Fernandes Silveira de Andrade ${ }^{1}$, Marcos Vinicius Locatelli ${ }^{1}$, Victório Birchler Tonini ${ }^{1}$ \\ \& Gustavo Haddad Souza Vieira ${ }^{1}$
}

\begin{abstract}
Resumo
Neste estudo, analisamos dados climáticos, um modelo de balanço hídrico e dados de caducifolia de árvores com o objetivo de determinar a fisionomia de uma floresta em São João de Petrópolis, região central do Espírito Santo, Brasil. Hipotetizamos que a floresta estudada seria um remanescente das florestas decíduas relatadas por naturalistas nos séculos XIX e XX, apesar do atual Mapa de Vegetação do Brasil indicar apenas florestas pluviais para a localidade. Dados obtidos de uma estação meteorológica local indicam que o clima é quente e com distribuição sazonal de chuvas. Embora a estação seca tenha durado seis meses em média (abril-setembro), períodos secos mais longos foram recorrentes nas últimas quatro décadas. Dentre 354 árvores amostradas no estrato superior da floresta no final da estação seca, $65,2 \%$ não possuíam folhagem, 18,1\% possuíam folhagem parcial e 16,7\% possuíam folhagem completa. A proporção de árvores sem folhagem foi superior a $60 \%$ em todas as classes de altura desse estrato. Esses atributos, bem como alguns registros de espécies arbóreas típicas de florestas estacionais, confirmam que a floresta é estacional decídua. Nossos resultados refinam o Mapa de Vegetação do Brasil e podem fomentar discussões sobre a controversa classificação das florestas do Estado do Espírito Santo.
\end{abstract}

Palavras-chave: caducifolia, deficit hídrico, fitofisionomia, sazonalidade de precipitação.

\begin{abstract}
In this study we analyzed climatic data, a water balance model, and data on tree deciduousness aiming to determine the physiognomy of a forest in São João de Petrópolis, central Espírito Santo, Brazil. We hypothesized that the studied forest stand would be a remnant of the deciduous forests that were reported by naturalists in both centuries XIX and XX, even though the current Vegetation Map of Brazil indicates only dense rainforests for this place. Data obtained from a local weather station indicate that climate in the site is hot and with seasonal distribution of rainfall. Although the dry season has lasted in average six months (AprilSeptember), dry periods longer than six months were recurrent throughout the four last decades. Among the 354 trees that were sampled in the upper storey at the end of the dry season, $65.2 \%$ had no foliage, $18.1 \%$ had partial foliage, and $16.7 \%$ had full foliage. Percentages of deciduous trees were higher than $60 \%$ in all height classes of the upper storey. These attributes, as well as some records of tree species that are typical of seasonal forests, confirm that the forest is seasonal deciduous. Our results refine the Vegetation Map of Brazil and may foment discussions about the controversial classification of the forests of Espírito Santo state. Key words: deciduousness, water deficit, phytophysiognomy, rainfall seasonality.
\end{abstract}

\footnotetext{
${ }^{1}$ Instituto Federal do Espírito Santo, Rod. ES-080, km 93, São João de Petrópolis, 29660-000, Santa Teresa, ES, Brasil.

${ }^{2}$ ORCID: < https://orcid.org/0000-0001-6597-869X>

3 Autor para correspondência: fsaiter@ifes.edu.br
} 
Florestas tropicais estacionais (FTE), também denominadas de florestas tropicais sazonalmente secas, são ecossistemas influenciados por climas sazonais caracterizados por precipitação média anual de até cerca de $1.600 \mathrm{~mm}$ e período seco (i.e. com precipitação média mensal $<100 \mathrm{~mm}$ ) geralmente de 5-6 meses (Bullock et al. 1995). Essas florestas apresentam dossel contínuo dominado por árvores, fato que as diferencia das savanas, normalmente mais abertas e com um estrato herbáceo rico em gramíneas ocupando o espaço entre árvores e arbustos (Rizzini 1979). Nas FTE, tanto a altura do dossel quanto a área basal tendem a ser menores do que aquelas registradas em florestas tropicais úmidas (Murphy \& Lugo 1986), e a abscisão foliar é uma das principais estratégias adotadas por plantas para lidar com o estresse fisiológico causado pela menor disponibilidade de água na estação seca (Bullock \& Solis-Magallanes 1990; Vico et al. 2015).

No Brasil, as FTE podem ser encontradas nos domínios fitogeográficos da Caatinga, do Cerrado e da Mata Atlântica (IBGE 2004). No sistema de classificação da vegetação brasileira de IBGE (2012), uma Floresta Estacional Decidual é aquela onde mais de $50 \%$ das árvores do estrato superior perdem totalmente as folhas no período seco (árvores caducifólias), enquanto na Floresta Estacional Semidecidual essa proporção deve estar entre 20 e $50 \%$. Por sua vez, a Floresta Estacional Perenifólia é aquela em que menos de $20 \%$ das árvores são caducifólias.

A ocorrência de FTE no Espírito Santo é oficialmente reconhecida no Mapa de Vegetação do Brasil (IBGE 2004), mas ali admite-se apenas o tipo semidecíduo (Floresta Estacional Semidecidual) no extremo sul (em áreas das bacias dos rios Itabapoana e Itapemirim) e em parte do centronoroeste (em porções das bacias dos rios Guandu, Pancas, Santa Maria do Rio Doce e São Mateus). Todavia, relatos encontrados na literatura do século XIX e do início do século XX levantam dúvidas sobre a existência de florestas com maior grau de caducifolia (florestas tropicais caducifólias ou decíduas; termos aqui considerados substitutos do nome Floresta Estacional Decidual adotado por IBGE 2012) no Espírito Santo.

Provavelmente, o primeiro relato dessas florestas no Espírito Santo é o trecho em latim "sylvis Catingas prov. Espiritu Santo" reproduzido no volume XV da Flora brasiliensis (Bentham 1876) a partir da etiqueta de um espécime de Cassia speciosa Schrad. [sinônimo de Senna macranthera
(DC. ex Collad.) H.S. Irwin \& Barneby], o qual foi coletado pelo Príncipe Maximiliano de Wied, um naturalista que visitou o Espírito Santo em 1815-1816 (Moraes 2009). Cerca de um século depois, em 1916-1917, o naturalista Philip von Luetzelburg relatou um gradiente na vegetação da margem sul do Rio Doce durante sua expedição até o Rio Mutum. Nas palavras do autor, “A vegetação da margem sul começa numa capoeira higrófila, passa depois a semi-xerófila e transforma-se por completo em vegetação xerófila com aspecto de caatinga, a que o baiano, sem dúvida, daria a denominação de caatinga suja." (Luetzelburg 1923, p. 111).

Na obra "Fitogeografia do Estado do Espírito Santo" publicada pelo naturalista Augusto Ruschi (Ruschi 1950) a ocorrência de dois tipos de "florestas mesófilas caducifólias" foi indicada em um mapa fitogeográfico (ver reprodução em Saiter et al. 2017). Segundo esse mapa, as "florestas dos tabuleiros caducifólias" ocupariam áreas mais interioranas de tabuleiros do Terciário ao norte do Rio Doce e as "matas xerófilas caducifólias", as quais Ruschi (1950) também denominou de "caatingas sujas" ou "caatingas primárias", estariam distribuídas na região central-noroeste, perfazendo cerca de $500 \mathrm{~km}^{2}$ nas bacias dos rios Pancas e Santa Joana. O autor acrescentou que "A forte tendência para [...] caatingas é impressionante, pois é muito extensa a área onde a precipitação se apresenta deficitária...” (Ruschi 1950, p. 90). Em excursões realizadas ao Espírito Santo em 1949 e 1950, o geógrafo Walter Alberto Egler registrou a ocorrência de manchas de vegetação xerófila entre Colatina e Baixo Guandu, para as quais também sugeriu a denominação de "caatinga" devido ao alto grau de caducifolia (Egler 1951). O autor alertou que tais manchas foram avistadas principalmente em encostas com solos mais rasos, mas admitiu que o gradiente vegetacional reconhecido por Luetzelburg (1923) já havia sido descaracterizado pela devastação de grande parte da vegetação original. Egler (1951, p. 62) ainda afirmou que “... para muitos constitui surprêsa o fato de que na maior parte da bacia do médio rio Doce se verifica a ocorrência de uma estação sêca que se prolonga por seis, oito ou mais meses do ano" [grafia original do autor].

Motivados pela controvérsia a respeito da existência de florestas decíduas no Espírito Santo, realizamos um estudo com o objetivo de determinar o tipo fisionômico de um fragmento florestal localizado em São João de Petrópolis (SJP), região 
central desse estado, onde, de acordo com o Mapa de Vegetação do Brasil (IBGE 2004), deveria existir a Floresta Ombrófila Densa ou Floresta Tropical Pluvial (Fig. 1; "shapefiles" disponíveis em $<$ https://doi.org/10.6084/m9.figshare.7565333. v1>). Para tanto, caracterizamos o clima da região por meio de dados de precipitação e temperatura coletados por uma estação meteorológica durante 41 anos, quantificamos o grau de caducifolia do componente arbóreo e utilizamos um extrato

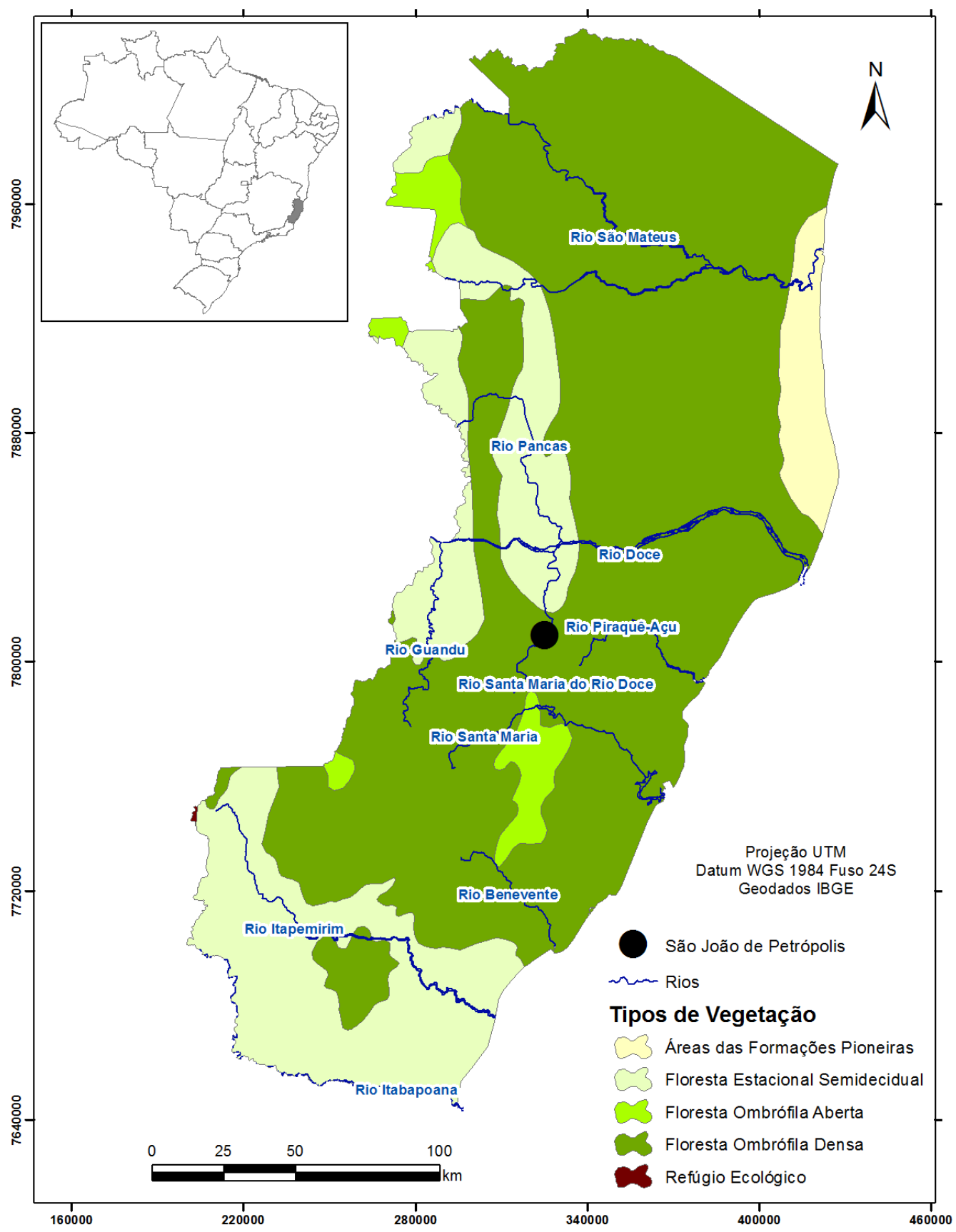

Figura 1 - Mapa de vegetação do Espírito Santo de acordo com IBGE (2004). A localização de São João de Petrópolis está marcada por um círculo preto na parte central do mapa.

Figure 1 - Vegetation map of Espírito Santo according to IBGE (2004). Location of São João de Petrópolis is marked by a black circle in the central part of map. 
de balanço hídrico sequencial para avaliar a repetição do padrão fisionômico encontrado ao longo da série histórica. Consideramos a hipótese de que o referido fragmento seria um testemunho das florestas decíduas relatadas por antigos naturalistas, uma vez que nos últimos sete anos os estratos superiores de florestas de SJP e arredores apresentaram padrão aparentemente decíduo.

SJP encontra-se no reverso da Serra do Castelo, uma extensão da Serra da Mantiqueira caracterizada por picos acima de $1.000 \mathrm{~m}$. A paisagem local é caracterizada por um vale amplo e plano cortado pelo Rio Santa Maria do Rio Doce, além de um conjunto de colinas rebaixadas e pequenas serras isoladas. A altitude na região normalmente varia entre 130 e 450 $\mathrm{m}$, mas pode alcançar até $700 \mathrm{~m}$ nos topos de algumas serras. A floresta estudada (Fig. 2; imagens adicionais disponíveis em <https:// doi.org/10.6084/m9.figshare.7528694.v1>) é localmente denominada de "Mata da Escola", possui aproximadamente 170 ha $\left(19^{\circ} 48^{\prime} 17^{\prime}\right.$ 'S, $\left.40^{\circ} 40^{\prime} 11^{\prime \prime} \mathrm{W}\right)$ e cobre parte de uma colina com altitude máxima de $350 \mathrm{~m}$.

Para a caracterização geral do clima, acessamos os dados originais das séries históricas de precipitação e temperatura da estação meteorológica localizada no Instituto Federal do Espírito Santo campus Santa Teresa (dados climatológicos brutos disponibilizados em formato de planilha em: $<$ https://doi.org/10.6084/m9.figshare.8061815>), a qual está instalada a $130 \mathrm{~m}$ de altitude e a cerca de $200 \mathrm{~m}$ da Mata da Escola. Os dados de precipitação média mensal compreenderam o período de 1977 a 2017 e os dados de temperatura média mensal os períodos de janeiro de 1977 a junho de 1998 e de 2013 a 2017. A falha na série histórica de temperatura ocorreu por problemas na operação da estação entre o final da década de 1990 e o ano de 2012. A caracterização do clima consistiu da interpretação de um climograma construído a partir dos dados médios mensais.

Para modelar o balanço hídrico sequencial de acordo com Thornthwaite \& Mather (1955), utilizamos os dados de precipitação média mensal e temperatura média mensal acima mencionados, além de dados complementares de temperatura de duas estações meteorológicas localizadas no município de Sooretama (a cerca de $90 \mathrm{~km}$ de SJP): estação Reserva Natural Vale (altitude $40 \mathrm{~m}$; série 1998-2009; dados disponíveis em Kierulff et al. 2015) e estação Sooretama do Instituto Nacional de Pesquisas Espaciais (altitude $70 \mathrm{~m}$; série
2010-2012; <http://sinda.crn.inpe.br/PCD/SITE/ novo/site/historico/index.php $>$ ). Os valores médios mensais de precipitação e temperatura foram reunidos, respectivamente, nos Apêndices 1 e 2, disponibilizados no material suplementar $<$ https:// doi.org/10.6084/m9.figshare.13073144.v1>. Para a modelagem, adotamos a planilha BHseq V6.4 (Rolim et al. 1998) e valores de capacidade máxima de armazenamento de água no solo (CAD), índice térmico e constante $a$ de, respectivamente, 100 $\mathrm{mm}, 134,40$ e 3,14 . Os extratos de deficiência, excedente, retirada e reposição do período $1977-$ 2017 foram representados em um único diagrama de balanço hídrico.

Para coleta de dados sobre o regime de renovação foliar da floresta, demarcamos 11 parcelas de $20 \times 25 \mathrm{~m}\left(500 \mathrm{~m}^{2}\right)$, totalizando 0,55 ha. Na seleção prévia dos locais das parcelas, evitamos aqueles caracterizados por grandes clareiras ou solos muito rasos nas imediações de afloramentos rochosos, bem como as bordas do fragmento e os trechos com vegetação em estágio inicial de regeneração. A amostragem foi realizada na segunda quinzena de agosto de 2017 , correspondendo ao terço final da estação seca regular.

Amostramos todas as árvores vivas com $\mathrm{CAP} \geq 20 \mathrm{~cm}$, independentemente da altura (dados originais das árvores disponíveis em <https:// doi.org/10.6084/m9.figshare.7528544.v3>). Em seguida, extraímos do conjunto de dados apenas as árvores do estrato superior (incluindo árvores emergentes), isto é, aquelas com nove metros de altura ou mais. Consideramos esse limite mínimo, pois, na estação chuvosa, quando a folhagem da floresta está plenamente estabelecida, as árvores menores do que nove metros são comumente sombreadas pelas copas de árvores maiores. Árvores com copas severamente danificadas foram excluídas da amostragem.

A amostragem consistiu da análise visual das copas com o auxílio de binóculo e classificação de cada árvore em uma das seguintes categorias: com folhagem completa, com folhagem parcial e sem folhagem. Consideramos como árvores com folhagem completa aquelas cujas copas apresentavam-se totalmente preenchidas por folhagem verde (sem sinais de senescência). Árvores sem folhagem foram aquelas totalmente desfolhadas ou com sinais de senescência (folhagem de coloração amarelada ou alaranjada) em toda a copa. Admitimos na categoria "com folhagem parcial" as árvores em situações intermediárias 
(com apenas parte da copa desfolhada ou parte das folhas amareladas).

Após a amostragem, calculamos os percentuais gerais de árvores em cada categoria fenológica e então classificamos a fisionomia da Mata da Escola de acordo com o regime de renovação foliar, considerando as proporções de árvores sem folhagem no estrato superior definidos por IBGE (2012), a saber: $>50 \%$, Decidual; 20 $50 \%$, Semidecidual; e $<20 \%$, Perenifólia. Também
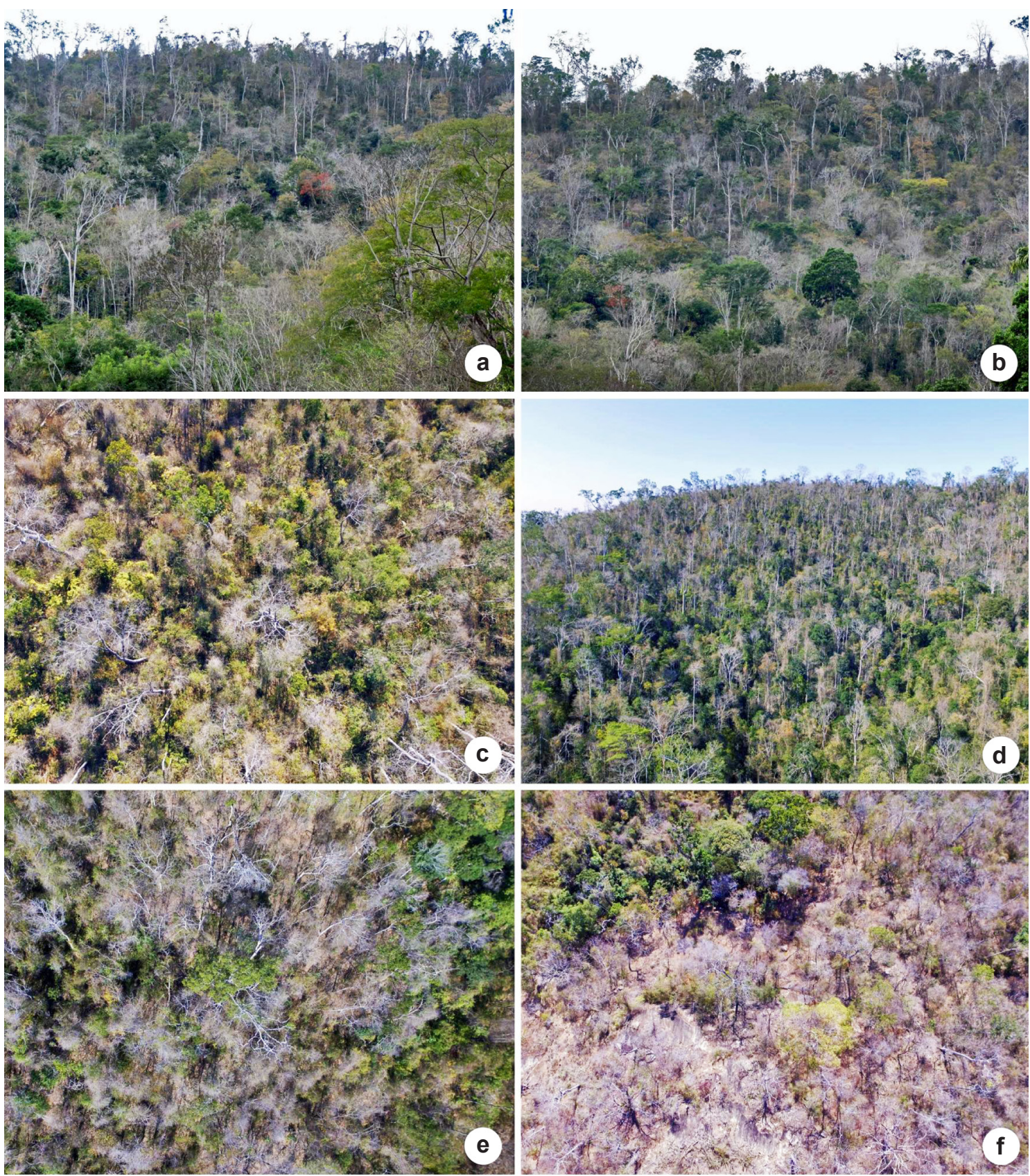

Figura 2 - a-f. Mata da Escola, São João de Petrópolis, Espírito Santo, na estação seca de 2017 - a,b. fotografias tomadas na segunda semana de agosto; $\mathrm{c}$-f. fotografias aéreas tomadas com uso de drone de quatro hélices na última semana de agosto.

Figure 2 - a-f. Mata da Escola, São João de Petrópolis, Espírito Santo, in the dry season of 2017 - a,b. photographs was taken in the second week of August; c-f. aerial photographs was taken in the last week of August by using drone quadcopter. 
calculamos os percentuais das categorias fenológicas por classes de altura $(9-12 ; 12-15 ; 15-18 ; 18-21$; $>21 \mathrm{~m}$ ) com o objetivo de identificar possíveis concentrações de árvores caducifólias em faixas do estrato superior.

As características gerais do clima de SJP foram representadas no climograma da Figura 3. Notamos que o clima local é quente e sazonalmente seco. Normalmente, a estação seca ocorre de abril a setembro e a estação chuvosa ocorre de novembro a janeiro. Fevereiro-março e outubro são períodos de transição entre as estações seca e chuvosa. A precipitação média anual é de $1.045,4 \mathrm{~mm}$. Na estação seca regular (seis meses) a precipitação média acumulada é de 193,8 mm, enquanto na

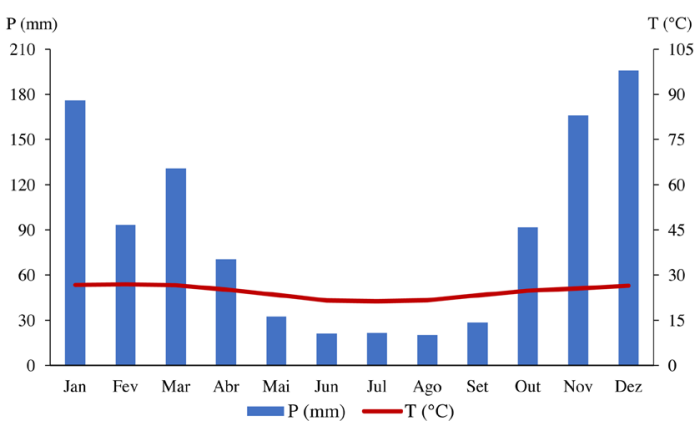

Figura 3 - Climograma de São João de Petrópolis, região central do Espírito Santo, baseado em dados de temperatura e precipitação (série histórica 19772017) da estação meteorológica do Instituto Federal do Espírito Santo campus Santa Teresa. P, precipitação média; T, temperatura média.

Figure 3 - Climatogram of São João de Petrópolis, central Espírito Santo, based on both temperature data and rainfall data (time-series 1977-2017) from the weather station of the Instituto Federal do Espírito Santo campus Santa Teresa. P, average rainfall; $\mathrm{T}$, average temperature. estação chuvosa (três meses) a média acumulada é de 537,8 mm (Apêndice 1, disponibilizado no material suplementar <https://doi.org/10.6084/ m9.figshare.13073144.v1>). O mês mais úmido é dezembro (195,8 mm em média) e o mês mais seco é agosto (20,1 mm em média; Apêndice 1, disponibilizado no material suplementar $<\mathrm{https}$ :/ doi.org/10.6084/m9.figshare.13073144.v1>). A temperatura média anual é de $24,4{ }^{\circ} \mathrm{C}$, mas as médias mensais variam de $21,3{ }^{\circ} \mathrm{C}$ (em julho) a $26,9{ }^{\circ} \mathrm{C}$ (em fevereiro; Apêndice 2, disponibilizado no material suplementar $<$ https://doi.org/10.6084/ m9.figshare.13073144.v1>). Junho, julho e agosto compreendem o trimestre mais frio $\left(<22{ }^{\circ} \mathrm{C} \mathrm{em}\right.$ cada mês) e dezembro, janeiro e fevereiro o trimestre mais quente $\left(>26,5^{\circ} \mathrm{C}\right.$ em cada mês; Apêndice 2 , disponibilizado no material suplementar $<$ https://doi. org/10.6084/m9.figshare.13073144.v1>).

O modelo de balanço hídrico sequencial (Fig. 4) indicou períodos com deficit hídrico em todos os 41 anos da série histórica. O deficit hídrico anual variou de 179,1 mm (em 1981) a 990,9 mm (em 2016). Em 2017, ano de realização deste estudo, a estação seca se estendeu até novembro, totalizando $524,9 \mathrm{~mm}$ de defict hídrico (308,6 $\mathrm{mm}$ acumulados até o final agosto). Anos muito secos (precipitação anual $<1.000 \mathrm{~mm}$ ) foram relativamente comuns (20 no total) e neles ocorreram períodos com deficit hídrico contínuo que superaram seis meses. Também nesses anos, deficit hídricos foram registrados na estação chuvosa regular (especialmente em janeiro, fevereiro e março), como resultado de veranicos. Períodos demasiadamente longos de deficit hídrico contínuo ocorreram em episódios extremos de seca, como em 1986 (11 meses), 1987-1989 (18 meses), 1993 (11 meses), 1994-1995 (11 meses), 2007 (11 meses) e 2014-2016 (20 meses). Anos muito chuvosos (> $1.400 \mathrm{~mm}$; apenas 1979, 1981, 1983,

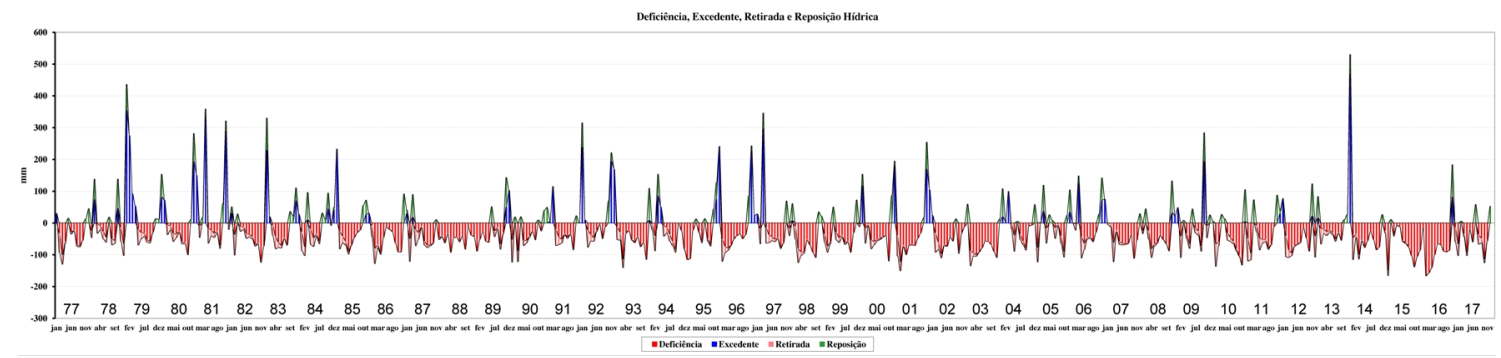

Figura 4 - Balanço hídrico sequencial para São João de Petrópolis (série histórica 1977-2017). No eixo horizontal são exibidas escalas para meses (inferior) e anos (superior) da série histórica.

Figure 4 - Sequential water balance for São João de Petrópolis (time-series 1977-2017). Scales for months (lower) and years (upper) of the time-series are displayed on the horizontal axis. 
1992 e 2013) foram atípicos e caracterizados por volumes extraordinários de precipitação em parte da estação chuvosa (por exemplo, $967 \mathrm{~mm}$ em janeirofevereiro de 1979 e $666 \mathrm{~mm}$ em dezembro de 2013; Apêndice 1, disponibilizado no material suplementar $<$ https://doi.org/10.6084/m9.figshare.13073144. v1>) e por estações secas com duração de 5 a 8 meses.

No total, amostramos 787 árvores na Mata da Escola, das quais 354 eram ocupantes do estrato superior. Dentre as árvores do estrato superior, $65,2 \%$ não possuíam folhagem, $18,1 \%$ possuíam folhagem incompleta e $16,7 \%$ possuíam folhagem completa (Tab. 1). A proporção de árvores totalmente desfolhadas foi maior que $60 \%$ em todas as classes de altura, demonstrando que o estrato superior como um todo apresentou o padrão decíduo (Tab. 1). Árvores dos estratos intermediário e inferior (altura $<9 \mathrm{~m}$ ) totalizaram 433 indivíduos. Se tais árvores fossem incorporadas na análise, a proporção de árvores caducifólias seria reduzida a 50,3\%, o que ainda estaria dentro do limite estabelecido por IBGE (2012) para a caracterização de uma Floresta Estacional Decidual.

A alta proporção de árvores sem folhagem revelou que na estação seca de 2017 a Mata da Escola apresentou fisionomia compatível com a tipologia de Floresta Estacional Decidual de IBGE (2012). Provavelmente, tal fisionomia foi recorrente nas estações secas das últimas quatro décadas, pois o extrato de balanço hídrico sequencial indicou a repetição de períodos secos expressivos no contexto de um regime sazonal de chuvas. Essa sazonalidade é resultado da conhecida dinâmica de deslocamentos do Anticiclone Subtropical do Atlântico Sul (ASAS), que ora estaciona sobre o sudeste do Brasil (na estação seca regular e nos veranicos) e bloqueia a passagem de massas de ar polar frio e úmido, ora migra para o Oceano Atlântico (na estação chuvosa) e libera a passagem dessas massas que formam frentes frias carregadas de chuva (ver Cupolillo et al. 2008).

Por sua vez, a configuração geomorfológica regional constitui um provável fator determinante dos modestos totais de precipitação que potencializam o deficit hídrico em SJP. A Serra do Castelo, que se ergue a leste de SJP, representa uma barreira orográfica para os ventos úmidos que sopram do litoral. O resultado disso é o ressecamento do reverso dessa serra (sotavento), constituindo um exemplo de efeito de sombra de chuva de acordo com o conceito de Glickman (2000).

A composição florística da Mata da Escola, embora ainda pouco conhecida, também corrobora o padrão decíduo de sua fisionomia. Dados disponíveis no Herbário Virtual da Flora e dos Fungos $(<\mathrm{http}$ ://inct.florabrasil.net/>) confirmam que ali ocorrem espécies típicas de FTE do sudeste e nordeste do Brasil. Dentre as espécies arbóreas, destacamos Anadenanthera colubrina (Vell.) Brenan, Amburana cearensis (Allemão) A.C.Sm., Cavanillesia umbellata Ruiz \& Pav., Cnidoscolus oligandrus (Müll.Arg.) Pax e Pterogyne nitens Tul..

$\mathrm{O}$ conjunto de características biológicas e ambientais aqui apresentado confirma a hipótese de que a Mata da Escola seria um remanescente das

Tabela 1 - Números totais e percentuais de árvores sem folhagem, com folhagem parcial e com folhagem completa, e suas respectivas distribuições por classes de altura no estrato superior de uma floresta em São João de Petrópolis, região central do Espírito Santo.

Table 1 - Total numbers and percentages of trees with no foliage, with partial foliage, and with full foliage, and their respective distribution by height classes in the upper storey of a forest in São João de Petrópolis, central Espírito Santo.

\begin{tabular}{lcccc}
\hline $\begin{array}{l}\text { Classes de altura } \\
\text { no estrato superior }(\mathbf{m})\end{array}$ & $\mathbf{N}$ & Sem folhagem & Com folhagem parcial & Com folhagem completa \\
\hline $9-12$ & 211 & $137(64,9 \%)$ & $42(19,9 \%)$ & $32(15,2 \%)$ \\
$12-15$ & 80 & $49(61,3 \%)$ & $14(17,5 \%)$ & $17(21,2 \%)$ \\
$15-18$ & 27 & $21(77,8 \%)$ & $3(11,1 \%)$ & $3(11,1 \%)$ \\
$18-21$ & 23 & $15(65,2 \%)$ & $4(17,4 \%)$ & $4(17,4 \%)$ \\
$>21$ & 13 & $9(69,2 \%)$ & $1(7,7 \%)$ & $3(23,1 \%)$ \\
Total & 354 & $231(65,2 \%)$ & $64(18,1 \%)$ & $59(16,7 \%)$ \\
\hline
\end{tabular}


florestas decíduas encontradas por naturalistas no centro-noroeste do Espírito Santo nos séculos XIX e $\mathrm{XX}$. Além disso, revela uma provável inconsistência do Mapa de Vegetação do Brasil (IBGE 2004), pois este indica a predominância de Floresta Ombrófila Densa (ou Floresta Tropical Pluvial) em SJP e arredores. De fato, devemos reconhecer que não seria possível representar algo restrito a SJP no referido mapa, pois este foi preparado na escala de 1:5.000.000 (IBGE 2004). Contudo, estudos já conjecturaram a respeito da dominância de florestas estacionais em todo o centro-noroeste do Espírito Santo (ver Saiter et al. 2015; Garbin et al. 2017), e esta região teria dimensão territorial passível de mapeamento na escala citada.

Não podemos, entretanto, afirmar que o centro-noroeste do Espírito Santo seria uma região exclusiva de florestas decíduas. Características da paisagem regional, bem como da vegetação remanescente ou regenerada, nos levam a suspeitar da ocorrência de outras fisionomias de florestas estacionais. Por exemplo, a presença de florestas estacionais semidecíduas e/ou perenifólias seria provável em topos de serras ( $>500-600 \mathrm{~m}$ ), onde temperaturas mais amenas (cerca de $3-4{ }^{\circ} \mathrm{C}$ mais baixas) reduziriam a evapotranspiração, e sobre os solos mais úmidos em fundos de vales de rios perenes.

De qualquer forma, nosso estudo representa a quebra de um paradigma - o de inexistência de florestas decíduas no Espírito Santo. Esperamos que nossas interpretações sobre SJP e a Mata da Escola estimulem as discussões a respeito da classificação das fisionomias florestais do Espírito Santo de modo que, no futuro, seja possível a construção de um mapa fitogeográfico mais alinhado com a realidade.

\section{Agradecimentos}

Agradecemos ao Dr. Ary Teixeira de Oliveira Filho, fonte de inspiração para este e outros estudos sobre a fitogeografia do Espírito Santo; e a Mateus K. Gering, a assessoria na captação das fotografias aéreas com uso de drone. M.M. dos Santos, E.F. Oza e M.V. Locatelli agradecem ao Instituto Federal do Espírito Santo, as bolsas de Iniciação Científica (PT5284/PIBIC05-2016, PT6308/PIBIC05-2017 e PT6309/PIBIC05-2017, respectivamente).

\section{Referências}

Bentham G (1876) Leguminosae II: Swartzieae et Caesalpinieae. In: Martius CFP \& Eichler AG (eds.) Flora brasiliensis. Frid. Fleischer, Lipsiae. Vol. 15, pars 2, pp. 1-254.
Bullock SH \& Solis-Magallanes JA (1990) Phenology of canopy trees of a tropical deciduous forest in Mexico. Biotropica 22: 22-35.

Bullock SH, Mooney HA \& Medina E (1995) Seasonally dry tropical forest. Cambridge University Press, Cambridge. 450p.

Cupolillo F, Abreu ML \& Vianello RL (2008) Climatologia da bacia do Rio Doce e sua relação com a topografia local. Geografias 4: 45-60.

Egler WA (1951) A zona pioneira ao norte do Rio Doce. Revista Brasileira de Geografia 2: 223-264.

Garbin ML, Saiter FZ, Carrijo TT \& Peixoto AL (2017) Breve histórico e classificação da vegetação capixaba. Rodriguésia 68: 1883-1894.

Glickman TS (2000) Glossary of Meteorology. $2^{\text {nd }}$ ed. American Meteorological Society, Boston. 855p.

IBGE (2004) Mapa de vegetação do Brasil. 3 ${ }^{a}$ ed. Instituto Brasileiro de Geografia e Estatística, Rio de Janeiro. Disponível em <https://www.ibge.gov. br/geociencias/informacoes-ambientais/vegetacao. html $>$. Acesso em 23 julho 2019.

IBGE (2012) Manual técnico da vegetação brasileira. Série Manuais Técnicos em Geociências 1, $2^{\mathrm{a}}$ ed. Instituto Brasileiro de Geografia e Estatística, Rio de Janeiro. 275p.

Kierulff MCM, Avelar LHS, Ferreira MES, Povoa KF \& Bérnils RS (2015) Reserva Natural Vale: história e aspectos físicos. Ciência \& Ambiente 49: 7-40.

Luetzelburg P. von (1923) Estudo Botânico do Nordéste. Vol. 2, n. 57, série I. Inspetoria Federal de Obras Contra as Sêcas, Rio de Janeiro. 126p.

Moraes PLR (2009) The brazilian herbarium of Maximilian, Prince of Wied. Neodiversity 4: 16-51.

Murphy PG \& Lugo AE (1986) Ecology of tropical dry forest. Annual Review of Ecology and Systematics 17: $67-88$.

Rizzini CT (1979) Tratado de fitogeografia do Brasil: aspectos sociológicos e florísticos. Vol. 2. Edusp, São Paulo. 374p.

Rolim GS, Sentelhas PC \& Barbieri V (1998) Planilhas no ambiente Excel $^{\mathrm{TM}}$ para os cálculos de balanços hídricos: normal, sequencial, de cultura e de produtividade real e potencial. Revista Brasileira de Agrometeorologia 6: 133-137.

Ruschi A (1950) Fitogeografia do estado de Esp. Santo: considerações gerais sobre a distribuição da flora no estado do E. Santo. Boletim do Museu de Biologia Prof. Mello Leitão (Série Botânica) 1: 1-353.

Saiter FZ, Eisenlohr PV, França GS, Stehmann JR, Thomas WW \& Oliveira-Filho AT (2015) Floristic units and their predictors unveiled in part of the Atlantic Forest hotspot: implications for conservation planning. Anais da Academia Brasileira de Ciências 87: 2031-2046.

Saiter FZ, Rolim SG, Jordy Filho S \& Oliveira-Filho AT (2017) Uma revisão sobre a controversa classificação fisionômica da Floresta de Linhares, norte do Espírito Santo. Rodriguésia 68: 1895-1907. 
Thornthwaite CW \& Mather JR (1955) The water balance. Publications in Climatology, Vol. VIII, n. 1. Drexel Institute of Technology, Laboratory of Climatology, Centerton. 104p.

Vico G, Thompson SE, Manzoni S, Molini A, Albertson
JD, Almeida-Cortez JS, Fay PA, Feng X, Guswa AJ, Liu H, Wilson TG \& Porporato A (2015) Climatic, ecophysiological, and phenological controls on plant ecohydrological strategies in seasonally dry ecosystems. Ecohydrology 8: 660-681. 